\title{
Efeito da Amonização sobre a Composição, a Retenção de Nitrogênio e a Conservação do Bagaço e da Ponta de Cana-de-açúcar ${ }^{1}$
}

\section{Ana Cristina Ladeira de Souza Gesualdi ${ }^{2}$, José Fernando Coelho da Silva ${ }^{3}$, Hernan Maldonado Vasquez ${ }^{3}$, Eleonora D'Ávila Erbesdobler ${ }^{4}$}

\begin{abstract}
RESUMO - Foram estudadas a composição bromatológica e a conservação de subprodutos da cana-de-açúcar tratados com $0,1,2$ e 4\% (N-amônia na matéria seca) nas formas de amônia anidra, uréia e sulfato de amônio, em arranjo fatorial e delineamento inteiramente casualizado. Não houve alteração no teor de matéria seca do bagaço, em função das fontes de amônia. As fontes de amônia promoveram decréscimo no teor de fibra em detergente neutro do bagaço, entretanto, só com o sulfato de amônia a ponta apresentou tal comportamento. Houve redução no teor de hemicelulose dos subprodutos tratados com uréia, em função dos níveis de amônia. A amonização com sulfato de amônio reduziu o teor de fibra em detergente ácido, principalmente, da ponta. Houve decréscimo no teor de celulose do bagaço tratado com amônia anidra. Os tratamentos resultaram em aumento no teor de proteína bruta de ambos subprodutos, em função dos níveis de amonia. O sulfato de amônio promoveu redução no teor de nitrogênio insolúvel em detergente ácido e maior retenção de nitrogênio nos dois subprodutos. Na maioria dos tratamentos, os períodos após abertura dos silos não alteraram o teor de nitrogênio total dos subprodutos. Os benefícios promovidos pelos tratamentos persistiram até o $48^{\circ}$ o dia para o bagaço e até o $24^{\circ}$ dia para a ponta.
\end{abstract}

Palavras-chave: fonte de amônia, nível de amônia, silagem, tratamento químico

\section{Effect of Ammoniation on the Composition, Retention and Conservation of Sugar Cane Bagasse and Tops}

\begin{abstract}
The chemical composition and the preservation of sugar cane byproducts treated with 0, 1, 2 and 4\% (N-ammonia in dry matter) using anhydrous ammonia, urea and ammonia sulfate, on a factorial arrangement in a completely randomized design were studied. No alteration was observed in dry matter content of sugar cane bagasse in function of sources of ammonia. The sources of ammonia decreased neutral detergent fiber (NDF) content of sugar cane bagasse, however; only the ammonia sulfate decreased the NDF of sugar cane tops. The hemicellulose content of the byproducts was reduced by urea treatment in function of ammonia levels. The ammoniation with ammonia sulfate decreased the acid detergent fiber content, mainly of sugar cane tops. The cellulose content of bagasse decreased with the anhydrous ammonia treatment. The treatments increased crude protein contents of both byproducts, in function of ammonia levels. The ammonia sulfate decreased the acid detergent insoluble nitrogen content, and showed higher nitrogen retention (NR) in both byproducts. In the majority of the treatments, periods after the opening of the silo showed no alteration in the NR of the byproducts. The benefits of ammonia treatments persisted for 48 days for the bagasse and for 24 days for the sugar cane tops.
\end{abstract}

Key Words: ammonia level, chemical treatment, ammonia source, silage

\section{Introdução}

A produção de açúcar e álcool gera inúmeros subprodutos de valor econômico, entre eles o bagaço e a ponta de cana-de-açúcar, os quais têm sido objeto de grande interesse como fonte de alimento para os ruminantes. Além disso, o corte da cana coincide com o período de escassez das pastagens e os subprodutos ficam disponíveis na época fria e seca do ano.

Os ruminantes ocupam lugar de destaque na agricultura, em face do aproveitamento dos produtos e resíduos agrícolas. Estes subprodutos, devido a sua flora microbiana, podem aproveitar material de baixo valor nutritivo (ANDRIGUETTO et al., 1981), mas, apesar de poderem ser utilizados por ruminantes, segundo PAIVA (1992), apresentam limitações, como elevados conteúdos dos chamados inibidores da digestão ou fatores antiqualitativos (lignina, sílica e compostos fenólicos) e baixos valores de nitrogênio, minerais e energia disponíveis.

O tratamento químico dos volumosos de baixa qualidade com amônia anidra, uréia e outros compostos

\footnotetext{
1 Parte da dissertação de mestrado em Zootecnia, apresentada pelo primeiro autor à UENF.

2 Mestre em Zootecnia, CCTA-UENF, Campos dos Goytacazes, RJ. E.mail: anaton@vicosa.com.br

3 Professor do CCTA-UENF, Campos dos Goytacazes, RJ, Bolsista do CNPq.

4 Aluna de mestrado em Zootecnia, CCTA-UENF, Campos dos Goytacazes, RJ. E.mail: Iola@uenf.br
} 
visa melhorar o valor nutritivo, com aumento de proteína bruta e digestibilidade da matéria seca, elevando, assim, o consumo e o desempenho dos animais, além de proporcionar melhor conservação do volumoso.

Segundo BUTOLO (1992), a utilização de subprodutos, na alimentação animal, complementaram a ração básica com a finalidade de substituir ingredientes tradicionais, equiparando-se ou aumentando a produtividade do animal, reduzindo-se custos de produção. Além disso, era coerente com os pricípios da conservação do meio ambiente.

O objetivo do presente trabalho foi a determinação dos efeitos de diferentes fontes e níveis de amônia sobre a composição bromatológica, a retenção de nitrogênio e a conservação do bagaço e da ponta de cana-de-açúcar (Saccharum officinarum L.).

\section{Material e Métodos}

A pesquisa foi conduzida na Universidade Estadual do Norte Fluminense, Campos dos Goytacazes, RJ. Foram utilizados 0, 1, 2 e 4\% de amônia anidra, uréia e sulfato de amônio (na matéria seca do subproduto armazenado). O bagaço e a ponta (picada em partículas de aproximadamente $2 \mathrm{~cm}$ ) foram colocados em silos de manilha de concreto com um metro de diâmetro por um metro de altura.

A amônia anidra foi colocada por meio de tubos perfurados. Com base no conhecimento prévio dos teores de matéria seca dos subprodutos, calculou-se a quantidade de amônia anidra a ser aplicada, correspondente a cada nível. Para controlar a quantidade de amônia anidra a ser aplicada, o botijão foi colocado sobre uma balança, interrompendo-se o fluxo do gás por meio de um registro, ao se atingir o peso desejado. A uréia e o sulfato de amônio foram dissolvidos em água numa proporção de 2:1 (duas partes de água), distribuídos por meio de um regador. Foram adicionados $20 \%$ de grão de soja moído aos silos que receberam uréia. Os silos permaneceram vedados por um período de 30 dias, ao fim do qual se procedeu à abertura.

Foram coletadas amostras antes dos subprodutos receberem os tratamentos; no dia da abertura dos silos (considerado período "zero") e com 3, 6, 12, 24 e 48 dias após abertura dos silos. A amostragem feita no $3^{\circ}$ dia foi utilizada para se determinar a composição bromatológica. Com as demais coletas, foram determinados os teores de nitrogênio total, para verificar a perda de nitrogênio após abertura dos silos.

Foram determinados os teores percentuais de matéria seca (MS), segundo SILVA (1990); fibra em detergente neutro (FDN) e fibra em detergente ácido (FDA), de acordo com o método de GEORING e VAN SOEST (1970), e a fração de hemicelulose, por diferença entre FDN e FDA. A celulose e a dosagem de nitrogênio $(\mathrm{N}$ x 6,25 = proteína bruta) foram feitas conforme descrito por SILVA (1990). O nitrogênio insolúvel em detergemte ácido (NIDA) foi determinado, utilizando-se a técnica descrita por GEORING e VAN SOEST (1970). A retenção de nitrogênio (RN) foi calculada com base nos teores de nitrogênio total dos subprodutos, antes e depois dos tratamentos (\% na MS).

As análises estatísticas foram realizadas segundo o delineamento exoerimental inteiramente casualizado, num arranjo fatorial $2 \times 3 \times 4$ (dois subprodutos, três fontes de amônia e quatro níveis de amônia), com três repetições, expresso pela fórmula:

$Y_{i j k}=\mu+\alpha_{i}+\beta_{j}+\gamma_{k}+(\alpha \beta)_{i j}+(\alpha \gamma)_{i k}+(\beta \gamma)_{j k}+\varepsilon_{i j k}$

em que $Y_{i j k}$ refere-se à resposta observada (efeito do subproduto "i", com a fonte "j", no nível "k"); $\mu$, à média geral; $\alpha_{i}$, ao efeito dos subprodutos ( $i=$ bagaço e ponta de cana-de-açúcar); $\beta_{\mathrm{j}}$, ao efeito das fontes de amônia (j = amônia anidra, uréia e sulfato de amônio); $\gamma_{\mathrm{k}}$, ao efeito dos níveis de amônia $(\mathrm{k}=0,1,2,4 \%) ;(\alpha \beta)_{\mathrm{ij}}$, ao efeito da interação do subproduto "i"com a fonte "j"; $(\alpha \gamma)_{\mathrm{ik}}$, ao efeito da interação do subproduto "i"com o nível "k"; $(\beta \gamma)_{j k}$, ao efeito da interação da fonte "j" com o nível "k"; $\varepsilon_{\mathrm{ijk}}$, ao erro experimental.

As comparações entre as médias dos subprodutos e de fontes foram feitas pelo teste Tukey, a 5\% de probabilidade (PIMENTEL GOMES, 1973). Os níveis de amônia dentro de cada fonte e para cada subproduto, dependendo da significância das interações entre os fatores, foram analisados por regressão. Para estudar a perda de nitrogênio após abertura dos silos, foi feita a análise de regressão do teor de nitrogênio (NT) após amonização, em relação aos períodos de $0,3,6,12,24$ e 48 dias após abertura dos silos no caso do bagaço e somente até o $24^{\circ}$ dia no caso da ponta. Na análise dos dados, foi utilizado o Sistema de Análises Estatísticas e Genéticas - SAEG (UNIVERSIDADE FEDERAL DE VIÇOSA - UFV, 1995). 


\section{Resultados e Discussão}

Houve interação $(\mathrm{P}<0,01)$ de tipo de subproduto e de fonte de amônia sobre o teor de MS de ambos subprodutos, porém não se constatou efeito $(\mathrm{P}>0,05)$ dos níveis de amônia. As fontes de amônia não influíram no teor de MS do bagaço tratado $(\mathrm{P}>0,05)$; enquanto a ponta apresentou menor teor de MS $(\mathrm{P}<0,05)$ quando tratada com uréia, em relação as outras fontes estudadas. Esta redução no teor de MS, em função das fontes, pode ser atribuída em parte à alta afinidade da amônia com a umidade do ar (FERREIRA, 1989). WYLIE e STEEN (1988) relataram que o teor de MS não foi alterado com a amonização.

A análise dos dados revelou efeito $(\mathrm{P}<0,01)$ do tipo de subproduto, da fonte e do nível de amônia sobre o teor de FDN. Analisando-se a Tabela 1, verifica-se que as equações descreveram reduções lineares $(\mathrm{P}<0,05)$ diferentes no teor de FDN do bagaço, em todas as fontes estudadas, com aumentos dos níveis. Com relação as fontes, o bagaço tratado com $1 \%$ de sulfato de amônio apresentou o menor teor de FDN $(86,94 \%)$. Na ponta, houve redução linear $(\mathrm{P}<0,05)$ no teor de FDN com elevação dos níveis, quando tratada com sulfato de amônio, não ocorrendo efeito $(\mathrm{P}>0,05)$ nas outras fontes utilizadas.
O sulfato de amônio também resultou um menor teor de FDN $(66,10 \%)$ na ponta, no nível 4\%. BUETTNER et al. (1982) atribuíram a diminuição de 8,5\% da FDN em feno de festuca com $3 \%$ de amônia anidra à solubilização da hemicelulose e da lignina. Decréscimos nos teores de FDN foram registrados por OLIVEROS et al. (1993), ao aplicarem 3\% de amônia anidra em palha de milho com $35 \%$ de umidade, e por FAHMY e KLOPFENSTEIN (1994), quando trabalharam com palha de milho, com $60 \%$ de umidade, com $6,6 \%$ de uréia mais $5,0 \%$ de $\mathrm{SO}_{2}$.

Não houve efeito $(\mathrm{P}>0,05)$ dos níveis de amônia sobre o teor de hemicelulose no bagaço tratado com amônia anidra e sulfato de amônio e na ponta com amônia anidra. Na interação fonte de amônia e tipo de subproduto, a amônia anidra resultou em menor $(\mathrm{P}<0,01)$ teor de hemicelulose no bagaço e em maior teor, na ponta (Tabela 2). As equações de regressão descrevem redução linear $(\mathrm{P}<0,01)$ no teor de hemicelulose, com elevação dos níveis no bagaço amonizado com uréia e na ponta com uréia e sulfato de amônio. Entre as fontes, o bagaço com $1 \%$ de amônia anidra e sulfato de amônio e a ponta com $1 \mathrm{e}$ $4 \%$ de uréia e de sulfato de amônio diferiram $(\mathrm{P}<0,05)$ das demais fontes. A redução no teor de hemicelulose é, provavelmente, atribuída à solubilizacão da

Tabela 1 - Teores percentuais médios de fibra em detergente neutro (Y, \% na MS) do bagaço e da ponta de cana-de-açúcar, em função dos níveis $(X)$ e fontes de amônia

Table 1 - Average percentage contents of neutral detergent fiber $(Y, \%$ in DM) of bagasse and sugar cane tops in function of levels ( $X)$ and sources of ammonia

\begin{tabular}{|c|c|c|c|c|c|c|c|}
\hline \multirow[b]{2}{*}{$\begin{array}{l}\text { Fonte } \\
\text { Source }\end{array}$} & \multicolumn{4}{|c|}{$\begin{array}{l}\text { Nível }(\%) \\
\text { Level }\end{array}$} & \multirow[b]{2}{*}{$\mathrm{ER}$} & \multirow[b]{2}{*}{$\mathrm{R}^{2}$} & \multirow[b]{2}{*}{$\mathrm{P}$} \\
\hline & 0 & 1 & 2 & 4 & & & \\
\hline \multicolumn{8}{|c|}{$\begin{array}{c}\text { Bagaço de cana } \\
\text { Sugar cane bagasse }\end{array}$} \\
\hline AA * & $94,46^{\mathrm{a}}$ & $93,52^{\mathrm{a}}$ & $91,82^{\mathrm{a}}$ & $90,31^{\mathrm{a}}$ & $\hat{Y}=94,39-1,06 x$ & 0,36 & 0,0391 \\
\hline $\mathrm{U} * *$ & $94,44^{\mathrm{a}}$ & $94,23^{\mathrm{a}}$ & $92,00^{\mathrm{a}}$ & $89,33^{\mathrm{a}}$ & $\hat{Y}=94,90-1,37 x$ & 0,40 & 0,0250 \\
\hline $\mathrm{SA} * * *$ & $94,50^{\mathrm{a}}$ & $86,94^{\mathrm{b}}$ & $87,03^{\mathrm{a}}$ & $86,29^{a}$ & $\hat{Y}=91,60-1,67 x$ & 0,44 & 0,0196 \\
\hline \multicolumn{8}{|c|}{$\begin{array}{l}\text { Ponta de cana } \\
\text { Sugar cane tpos }\end{array}$} \\
\hline AA * & $77,22^{\mathrm{a}}$ & $81,30^{\mathrm{a}}$ & $75,77^{\mathrm{a}}$ & $76,77^{\mathrm{a}}$ & $\hat{Y}=78,69$ & - & NS \\
\hline $\mathrm{U} * *$ & $77,20^{\mathrm{a}}$ & $76,24^{\mathrm{ab}}$ & $78,97^{\mathrm{a}}$ & $76,64^{\mathrm{a}}$ & $\hat{Y}=77,46$ & - & NS \\
\hline $\mathrm{SA} * * *$ & $77,19^{\mathrm{a}}$ & $74,81^{\mathrm{b}}$ & $70,59^{a}$ & $66,10^{\mathrm{b}}$ & $\hat{Y}=77,16-2,84 x$ & 0,81 & 0,0001 \\
\hline
\end{tabular}

Médias seguidas das mesmas letras, na coluna, não diferem pelo o teste Tukey $(P>0,05)$.

$\mathrm{NS}=$ não-significativo $(\mathrm{P}>0,05)$.

Means followed by same letters, within a column, did not differ, by Tukey test $(P>.05)$.

NS Non significant.

* Anhydrous ammonia.

** Urea.

*** Ammoniasulfate. 
SOUZA GESUALDI et al.

Tabela 2 - Teores percentuais médios de hemicelulose (Y, \% na MS) do bagaço e da ponta de cana-de-açúcar, em função dos níveis $(X)$ e fontes de amônia

Table 2 - Average percent contents of hemicellulose $(Y, \%$ in $D M)$ of bagasse and sugar cane tops in function of levels $(X)$ and sources of ammonia

\begin{tabular}{|c|c|c|c|c|c|c|c|}
\hline \multirow[b]{2}{*}{$\begin{array}{l}\text { Fonte } \\
\text { Source }\end{array}$} & \multicolumn{4}{|c|}{$\begin{array}{c}\text { Nível (\%) } \\
\text { Level }\end{array}$} & \multirow[b]{2}{*}{$\mathrm{ER}$} & \multirow[b]{2}{*}{$\mathrm{R}^{2}$} & \multirow[b]{2}{*}{$\mathrm{P}$} \\
\hline & 0 & 1 & 2 & 4 & & & \\
\hline \multicolumn{8}{|c|}{$\begin{array}{c}\text { Bagaço de cana } \\
\text { Sugar cane bagasse }\end{array}$} \\
\hline $\mathrm{AA} *$ & $35,06^{\mathrm{a}}$ & $26,43^{b}$ & $29,36^{\mathrm{a}}$ & $27,65^{\mathrm{a}}$ & $\hat{Y}=31,95$ & - & NS \\
\hline $\mathrm{U} * *$ & $35,00^{\mathrm{a}}$ & $34,05^{\mathrm{a}}$ & $31,88^{\mathrm{a}}$ & $30,12^{\mathrm{a}}$ & $\hat{\mathrm{Y}}=35,01-1,27 \mathrm{x}$ & 0,58 & 0,0041 \\
\hline $\mathrm{SA} * * *$ & $35,10^{\mathrm{a}}$ & $29,69^{b}$ & $27,44^{\mathrm{a}}$ & $30,82^{\mathrm{a}}$ & $\hat{Y}=32,24$ & - & NS \\
\hline \multicolumn{8}{|c|}{$\begin{array}{l}\text { Ponta de cana } \\
\text { Sugar cane tops }\end{array}$} \\
\hline $\mathrm{AA} *$ & $32,50^{\mathrm{a}}$ & $35,47^{\mathrm{a}}$ & $29,96^{\mathrm{a}}$ & $32,00^{\mathrm{a}}$ & $\hat{Y}=33,28$ & - & NS \\
\hline $\mathrm{U} * *$ & $33,00^{\mathrm{a}}$ & $29,47^{b}$ & $31,50^{\mathrm{a}}$ & $26,38^{b}$ & $\hat{Y}=32,31-1,34 x$ & 0,59 & 0,0035 \\
\hline $\mathrm{SA} * * *$ & $32,00^{\mathrm{a}}$ & $30,03^{\mathrm{b}}$ & $28,55^{\mathrm{a}}$ & $27,53^{\mathrm{b}}$ & $\hat{Y}=31,72-1,18 x$ & 0,64 & 0,0018 \\
\hline $\begin{array}{ll} & \text { Médias } \\
\text { NS } & \text { Não-si } \\
& \text { Means } \\
\text { NS } & \text { Non sig } \\
* & \text { Anhydrc } \\
* * & \text { Urea. } \\
* \star * & \text { Ammon }\end{array}$ & $\begin{array}{l}\text { las mesm } \\
P>0,05) \text {. } \\
\text { ame letters, }\end{array}$ & $\begin{array}{l}\text { na colun } \\
\text { nn, did not }\end{array}$ & iferem pe & Tukey (P & & & \\
\hline
\end{tabular}

hemicelulose pela amônia, conforme relatado por WYLIE e STEEN (1988).

Houve decréscimo $(\mathrm{P}<0,05)$ no teor de FDA, quando a ponta foi tratada com sulfato de amônio nos níveis de 2 e $4 \%$, o mesmo ocorrendo quando o bagaço foi tratado com uréia e sulfato de amônio nos níveis de 1 e 4\%, em relação aos outros tratamentos. TEIXEIRA (1990) relatou que a queda na concentração de FDA do capim-elefante pode ser atribuída a alguma solubilização de celulose e lignina ocorrida. Não houve alteração $(\mathrm{P}>0,05)$ no teor de FDA do bagaço, em função dos níveis. Na ponta, não houve efeito significativo dos níveis, quando se utilizou a amônia anidra; entretanto, a uréia promoveu acréscimo linear $(\mathrm{P}<0,01)$ e o sulfato de amônio, redução linear $(\mathrm{P}<0,01)$ do teor de FDA (Tabela 3). A maioria dos autores não observou alteração na fração de FDA em diversos materiais tratados com amônia anidra (BONJARDIM et al., 1992; PAIVA et al., 1995b; REIS et al., 1995; ROSA et al., 1995).

$\mathrm{Na}$ Tabela 4, observam-se os resultados da interação de nível de amônia e tipo de subproduto sobre o teor de celulose dos materiais estudados. Houve diferença entre os subprodutos com relação ao teor de celulose, quando se utilizaram níveis de 1 e $2 \%$ de amônia. A análise de regressão não revelou efeito $(P>0,05)$ dos níveis no teor de celulose do bagaço, enquanto na ponta o efeito foi quadrático $(\mathrm{P}<0,05)$, apesar do baixo coeficiente de determinação $\left(R^{2}=0,19\right)$. Esta equação permitiu estimar um ponto de máxima de $62,3 \%$ de celulose, no nível de $1,7 \%$ de amônia.

Conforme resultados encontrados por PIRES (1995), os aumentos relatados para os teores de FDA e celulose, normalmente, devem-se à diminuição de outros compostos como FDN e hemicelulose, correspondendo, assim, a aumentos proporcionais. Com relação à interação de nível e fonte de amônia, os níveis não alteraram $(\mathrm{P}>0,05)$ o teor de celulose dos subprodutos tratados. A amônia anidra ao nível de $1 \%$ resultou em $59,67 \%$ de celulose, diferindo das demais fontes, quando usadas neste mesmo nível. Ao nível de $4 \%$ não houve diferença entre fontes de amônia. REIS et al. (1991), BONJARDIM et al. (1992), QUEIROZ et al. (1992a) revelaram que a tendência do teor de celulose foi a de permanecer inalterada com a amonização.

Houve interação $(\mathrm{P}<0,01)$ de fonte de amônia e tipo de subproduto, sendo que as fontes não influíram $(\mathrm{P}>0,05)$ no teor de $\mathrm{PB}$ do bagaço, provavelmente, em função do baixo teor de umidade desse material. Entretanto, a ponta apresentou maior $(\mathrm{P}<0,05)$ teor 
512 Rev. bras. zootec.

Tabela 3 - Teores percentuais médios de fibra em detergente ácido (Y, \% na MS) do bagaço e da ponta de cana-de-açúcar, em função dos níveis $(X)$ e fontes de amônia

Table 3 - Percentage contents means of acid detergent fiber ( $Y, \%$ in DM) of bagasse and sugar cane tops in function of levels ( $X)$ and sources of ammonia

\begin{tabular}{|c|c|c|c|c|c|c|c|}
\hline \multirow[b]{2}{*}{$\begin{array}{l}\text { Fonte } \\
\text { Source }\end{array}$} & \multicolumn{4}{|c|}{$\begin{array}{c}\text { Nível }(\%) \\
\text { Level }\end{array}$} & \multirow[b]{2}{*}{$\mathrm{ER}$} & \multirow[b]{2}{*}{$\mathrm{R}^{2}$} & \multirow[b]{2}{*}{$\mathrm{P}$} \\
\hline & 0 & 1 & 2 & 4 & & & \\
\hline \multicolumn{8}{|c|}{$\begin{array}{c}\text { Bagaço de cana } \\
\text { Sugar cane bagasse }\end{array}$} \\
\hline $\mathrm{AA} *$ & $59,40^{\mathrm{a}}$ & $66,58^{a}$ & $62,46^{\mathrm{a}}$ & $61,64^{\mathrm{a}}$ & $\hat{Y}=62,44$ & - & NS \\
\hline $\mathrm{U} * *$ & $59,35^{\mathrm{a}}$ & $61,12^{\mathrm{ab}}$ & $60,12^{\mathrm{a}}$ & $59,20^{\mathrm{ab}}$ & $\hat{Y}=60,54$ & - & NS \\
\hline $\mathrm{SA} * * *$ & $59,45^{\mathrm{a}}$ & $57,24^{\mathrm{b}}$ & $59,59^{\mathrm{a}}$ & $55,47^{\mathrm{b}}$ & $\hat{Y}=59,36$ & - & NS \\
\hline \multicolumn{8}{|c|}{$\begin{array}{l}\text { Ponta de cana } \\
\text { Sugar cane tops }\end{array}$} \\
\hline $\mathrm{AA} *$ & $44,80^{\mathrm{a}}$ & $46,73^{\mathrm{a}}$ & $46,02^{\mathrm{ab}}$ & $44,78^{b}$ & $\hat{\mathrm{Y}}=45,78$ & - & NS \\
\hline $\mathrm{U} * *$ & $44,70^{\mathrm{a}}$ & $47,17^{\mathrm{a}}$ & $47,47^{\mathrm{a}}$ & $50,62^{\mathrm{a}}$ & $\hat{\mathrm{Y}}=45,08+1,38 \mathrm{x}$ & 0,53 & 0,0069 \\
\hline $\mathrm{SA} * * *$ & $44,73^{\mathrm{a}}$ & $44,78^{\mathrm{a}}$ & $42,04^{\mathrm{b}}$ & $38,32^{\mathrm{c}}$ & $\hat{\mathrm{Y}}=45,49-1,73 \mathrm{x}$ & 0,73 & 0,0004 \\
\hline \multicolumn{8}{|c|}{ 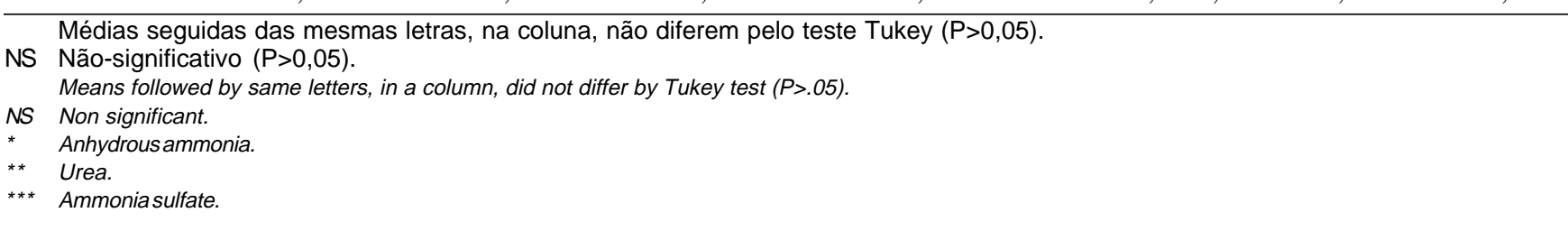 } \\
\hline
\end{tabular}

Tabela 4 - Efeito da interação de níveis de amônia (X) e tipos de subprodutos e efeito da interação de níveis (X) e fontes de amônia sobre o teor de celulose ( $\mathrm{Y}, \%$ na $\mathrm{MS})$

Table 4 - Interaction effect of the ammonia levels $(X)$ and byproducts types, and interaction effect of levels $(X)$ and sources of ammonia on the cellulose content ( $Y, \%$ in DM)

\begin{tabular}{|c|c|c|c|c|c|c|c|}
\hline \multirow[b]{2}{*}{$\begin{array}{l}\text { Fonte } \\
\text { Source }\end{array}$} & \multicolumn{4}{|c|}{$\begin{array}{l}\text { Nível }(\%) \\
\text { Level }\end{array}$} & \multirow[b]{2}{*}{$\mathrm{ER}$} & \multirow[b]{2}{*}{$\mathrm{R}^{2}$} & \multirow[b]{2}{*}{$\mathrm{P}$} \\
\hline & 0 & 1 & 2 & 4 & & & \\
\hline \multirow{2}{*}{$\begin{array}{l}\text { Bagaço de cana } \\
\text { Sugar cane bagasse } \\
\text { Ponta de cana } \\
\text { Sugar cane tpos } \\
\end{array}$} & $59,87^{a}$ & $57,39^{b}$ & $55,79^{b}$ & $58,04^{\mathrm{a}}$ & $\hat{Y}=59,45$ & - & NS \\
\hline & $58,66^{\mathrm{a}}$ & $63,06^{\mathrm{a}}$ & $61,12^{\mathrm{a}}$ & $57,14^{\mathrm{a}}$ & $\hat{Y}=59,18+3,53 x-1,02 x^{2}$ & 0,19 & 0,0334 \\
\hline & \multicolumn{4}{|c|}{$\begin{array}{c}\text { Níveis }(\%) \\
\text { Levels }\end{array}$} & & & \\
\hline $\begin{array}{l}\text { Fontes } \\
\text { Sources }\end{array}$ & 0 & 1 & 2 & 4 & ER & $\mathrm{R}^{2}$ & $\mathrm{P}$ \\
\hline$\overline{\mathrm{AA} *}$ & $60,00^{\mathrm{a}}$ & $59,67^{b}$ & $56,17^{b}$ & $58,11^{\mathrm{a}}$ & $\hat{Y}=57,44$ & - & NS \\
\hline $\mathrm{U} * *$ & $59,30^{\mathrm{a}}$ & $63,52^{\mathrm{a}}$ & $61,63^{\mathrm{a}}$ & $57,13^{\mathrm{a}}$ & $\hat{\mathrm{Y}}=61,87$ & - & NS \\
\hline $\mathrm{SA} * * *$ & $59,27^{\mathrm{a}}$ & $61,49^{a}$ & $57,58^{\mathrm{ab}}$ & $57,55^{\mathrm{a}}$ & $\hat{Y}=60,17$ & - & NS \\
\hline $\begin{array}{ll} & \text { Médias seguidas d } \\
\text { NS } & \text { Não-significativo ( } \\
& \text { Averages followed by } \\
\text { NS } & \text { Non significant. } \\
* & \text { Anhydrousammonia. } \\
* & \text { Urea. } \\
\text { *** } & \text { Ammoniasulfate. }\end{array}$ & $\begin{array}{l}\text { mesmas } \\
0,05) \text {. } \\
\text { ame letters, }\end{array}$ & $\begin{array}{l}\text { as, na col } \\
\text { umn of in th }\end{array}$ & não difere & $\begin{array}{l}\text { lo teste } T \\
\text { ey test }(P>\text {. }\end{array}$ & > $>0,05)$ & & \\
\hline
\end{tabular}


de PB, quando amonizada com sulfato de amônio. Isso pode ser explicado graças ao teor de umidade da ponta, associado à fonte de enxofre. Tais procedimentos são utilizados para promover maior retenção de nitrogênio em volumosos amonizados (Dryden e Leng, 1986, citados por PAIVA, 1992). A maior retenção de nitrogênio resultará, conseqüentemente, em melhoria no teor de PB ( $\mathrm{N}$ x 6,25). Também os subprodutos possuíam, inicialmente, teores de $\mathrm{PB}$ diferentes, daí a diferença observada entre eles. Segundo TEIXEIRA (1990), o nitrogênio é retido por meio de uma reação da amônia com a água retida nos materiais e/ou uma reação de amonólise entre a amônia e um éster, produzindo amida. A retenção de nitrogênio seria, portanto, limitada, primeiramente pela quantidade de água presente no material e pelo número de ligações éster suscetível à amonólise. $\mathrm{Na}$ Tabela 5 é apresentado aumento linear $(\mathrm{P}<0,01)$ no teor de PB, com elevação dos níveis de amônia em ambos subprodutos e para todas as fontes.

Não houve diferença entre as fontes sobre o teor de PB do bagaço; porém, a ponta tratada com sulfato de amônio promoveu acréscimo de 48,45; 100,48; e $250,84 \%$, respectivamente, para os níveis de 1,2 e $4 \%$, quando comparada com as outras fontes.
GROSSI et al. (1993) avaliaram os efeitos da adição de amônia anidra (3\% da MS) ou da uréia $(5,4 \%$ da MS) às palhas de triticale e aveia, à casca de arroz e ao feno de coastcross, em que os teores de PB, em todos os volumosos, aumentaram com os tratamentos. Resultados semelhantes foram encontrados por ALIBES et al. (1984). Segundo NASCIMENTO e BONA NASCIMENTO (1997), a amonização do bagaço de cana, da casca de arroz e da bagana de carnaúba com 5\% de uréia, resultou em aumentos nos percentuais de PB, nos três resíduos.

Houve interação de nível de amônia e tipo de subproduto $(\mathrm{P}<0,01)$ sobre os teores de NIDA dos materiais tratados. As equações, na Tabela 6 , mostram comportamento quadrático no teor de NIDA com aumento dos níveis.

Estima-se que o ponto de mínima de $18,40 \%$ ocorreria, se fosse usado nível de 6,4\% de amônia, no caso do bagaço e de $18,90 \%$ de NIDA para a ponta, se fosse usado 5,9\% de amônia. A redução no teor de NIDA foi mais acentuada no bagaço. Segundo REIS et al. (1993), a amonização com 3\% de amônia anidra, de resíduos de aveia e trigo, não influiu no teor de NIDA. Os valores de NIDA têm sido correlacionados à disponibilidade de compostos nitrogenados para o

Tabela 5 - Teores percentuais médios de proteína bruta (Y, \% na MS) do bagaço e da ponta de cana-de-açúcar, em função dos níveis $(X)$ e fontes de amônia

Table 5 - Average percent contents of crude protein $(Y, \%$ in DM) of bagasse and sugar cane tops in function of levels $(X)$ and sources of ammonia

\begin{tabular}{|c|c|c|c|c|c|c|c|}
\hline \multirow[b]{2}{*}{$\begin{array}{l}\text { Fonte } \\
\text { Source }\end{array}$} & \multicolumn{4}{|c|}{$\begin{array}{l}\text { Nível }(\%) \\
\text { Level }\end{array}$} & \multirow[b]{2}{*}{$\mathrm{ER}$} & \multirow[b]{2}{*}{$\mathrm{R}^{2}$} & \multirow[b]{2}{*}{$\mathrm{P}$} \\
\hline & 0 & 1 & 2 & 4 & & & \\
\hline \multicolumn{8}{|c|}{$\begin{array}{c}\text { Bagaço de cana } \\
\text { Sugar cane bagasse }\end{array}$} \\
\hline $\mathrm{AA} *$ & $2,07^{\mathrm{a}}$ & $4,03^{\mathrm{a}}$ & $4,42^{\mathrm{a}}$ & $6,81^{\mathrm{a}}$ & $\hat{Y}=2,23+1,12 x$ & 0,95 & 0,0000 \\
\hline $\mathrm{U} * *$ & $2,10^{\mathrm{a}}$ & $3,78^{\mathrm{a}}$ & $4,08^{a}$ & $7,04^{\mathrm{a}}$ & $\hat{Y}=2,17+1,89 x$ & 0,92 & 0,0000 \\
\hline $\mathrm{SA} * * *$ & $2,07^{\mathrm{a}}$ & $4,91^{\mathrm{a}}$ & $3,43^{\mathrm{a}}$ & $9,46^{\mathrm{a}}$ & $\hat{Y}=2,01+1,69 x$ & 0,74 & 0,0003 \\
\hline \multicolumn{8}{|c|}{$\begin{array}{l}\text { Ponta de cana } \\
\text { Sugar cane tops }\end{array}$} \\
\hline $\mathrm{AA} *$ & $8,35^{\mathrm{a}}$ & $10,25^{\mathrm{b}}$ & $9,76^{b}$ & $12,90^{\mathrm{b}}$ & $\hat{Y}=8,89+1,05 x$ & 0,51 & 0,0092 \\
\hline $\mathrm{U} * *$ & $8,36^{\mathrm{a}}$ & $8,65^{\mathrm{b}}$ & $9,48^{b}$ & $10,34^{\mathrm{b}}$ & $\hat{Y}=8,30+0,52 x$ & 0,67 & 0,0011 \\
\hline $\mathrm{SA} * * *$ & $8,38^{\mathrm{a}}$ & $12,44^{\mathrm{a}}$ & $16,80^{\mathrm{a}}$ & $29,40^{\mathrm{a}}$ & $\hat{Y}=7,47+5,30 x$ & 0,87 & 0,0000 \\
\hline \multicolumn{8}{|c|}{$\begin{array}{l}\text { Médias seguidas das mesmas letras, na coluna, não diferem pelo teste Tukey }(P>0,05) \text {. } \\
\text { NS Não-significativo }(P>0,05) \text {. } \\
\text { Means followed by the same letters, in a column, did not differ by Tukey test }(P>05) \text {. } \\
\text { NS Non significant. } \\
\text { * Anhydrous ammonia. } \\
\text { ** Urea. } \\
\text { *** Ammonia sulfate. }\end{array}$} \\
\hline
\end{tabular}


514 Rev. bras. zootec.

Tabela 6 - Efeito da interação de níveis de amônia (X) e tipos de subprodutos e efeito da interação de níveis (X) e fontes de amônia sobre o teor de nitrogênio insolúvel em detergente ácido (Y, \% no NT)

Table 6 - Interaction effect of ammonia levels $(X)$ and byproducts types and interaction effect of levels $(X)$ and sources of ammonia on insoluble nitrogen acid detergent content $(Y, \%$ in $T N)$

\begin{tabular}{|c|c|c|c|c|c|c|c|}
\hline \multirow[b]{2}{*}{$\begin{array}{l}\text { Fonte } \\
\text { Source }\end{array}$} & \multicolumn{4}{|c|}{$\begin{array}{l}\text { Nível }(\%) \\
\text { Level }\end{array}$} & \multirow[b]{2}{*}{$\mathrm{ER}$} & \multirow[b]{2}{*}{$\mathrm{R}^{2}$} & \multirow[b]{2}{*}{$\mathrm{P}$} \\
\hline & 0 & 1 & 2 & 4 & & & \\
\hline Bagaço de cana & $67,81^{\mathrm{a}}$ & $43,07^{\mathrm{a}}$ & $43,80^{\mathrm{a}}$ & $25,56^{\mathrm{a}}$ & $\hat{Y}=84,68-20,72 x+1,62 x^{2}$ & 0,70 & 0,0000 \\
\hline $\begin{array}{l}\text { Sugar cane bagasse } \\
\text { Ponta de cana } \\
\text { Sugar cane tops }\end{array}$ & $29,42^{\mathrm{b}}$ & $26,04^{b}$ & $22,23^{\mathrm{b}}$ & $20,59^{a}$ & $\hat{Y}=34,33-5,21 x+0,44 x^{2}$ & 0,17 & 0,0443 \\
\hline & \multicolumn{4}{|c|}{$\begin{array}{c}\text { Nível (\%) } \\
\text { Level }\end{array}$} & & & \\
\hline $\begin{array}{l}\text { Fonte } \\
\text { Source }\end{array}$ & 0 & 1 & 2 & 4 & ER & $\mathrm{R}^{2}$ & $\mathrm{P}$ \\
\hline $\begin{array}{l}\mathrm{AA} * \\
\mathrm{U} * * \\
\mathrm{SA} * * *\end{array}$ & $\begin{array}{l}48,60^{\mathrm{a}} \\
49,01^{\mathrm{a}} \\
48,61^{\mathrm{a}}\end{array}$ & $\begin{array}{l}36,94^{\mathrm{a}} \\
39,97^{\mathrm{a}} \\
26,74^{\mathrm{b}}\end{array}$ & $\begin{array}{l}36,37^{\mathrm{a}} \\
36,01^{\mathrm{a}} \\
26,67^{\mathrm{b}}\end{array}$ & $\begin{array}{l}27,48^{\mathrm{a}} \\
30,61^{\mathrm{a}} \\
11,14^{\mathrm{b}}\end{array}$ & $\begin{array}{l}\hat{Y}=45,72-4,78 x \\
\hat{Y}=46,24-4,25 x \\
\hat{Y}=42,97-8,39 x\end{array}$ & $\begin{array}{l}0,25 \\
0,19 \\
0,41\end{array}$ & $\begin{array}{l}0,0127 \\
0,0309 \\
0,0008\end{array}$ \\
\hline
\end{tabular}

Médias seguidas das mesmas letras, na coluna, não diferem pelo teste Tukey $(P>0,05)$.

NS Não-significativo $(P>0,05)$.

Means followed by same letters, column of in the, did not differ by Tukey test (P>.05).

NS Non significant.

* Anhydrousammonia.

** Urea.

*** Ammonia sulfate.

animal. O nitrogênio retido na forma de NIDA em forragens amonizadas é pouco utilizado pelos animais (PAIVA, 1992). Na Tabela 6, é analisada a interação de nível e fonte de amônia sobre os teores de NIDA dos subprodutos. Observam-se decréscimos lineares diferenciados em cada uma das fontes, com aumento dos níveis, apesar dos baixos valores de $\mathrm{R}^{2}$. O sulfato de amônia promoveu reduções $(\mathrm{P}<0,01)$ de 44,99 ; 45,13; e 77,08\% nos teores de NIDA, respectivamente, para os níveis 1,2 e $4 \%$, quando comparado com as outras duas fontes nestes mesmos níveis. Segundo PIRES (1995), os altos teores de NIDA foram resultantes da ocorrência da elevação de temperaturas, que favoreceram a reação entre o nitrogênio e os carboidratos, que se acumularam nas fibras, denominada de Reação de Maillard.

$\mathrm{Na}$ interação de nível de amônia e tipo de subproduto, na Tabela 7, não houve diferença $(\mathrm{P}>0,05)$ na RN do bagaço, entre os níveis estudados, entretanto, ocorreu comportamento quadrático $(\mathrm{P}<0,01)$ na $\mathrm{RN}$ da ponta, com aumentos dos níveis. O bagaço apresentou menor RN $(\mathrm{P}<0,05)$, em virtude de seu baixo teor de umidade. Pode-se estimar para a ponta um valor mínimo de 27,30\% de RN com 2,8\% de amônia.
PAIVA et al. (1995a) observaram que a RN na palhada de milho reduziu, quando o nível de amônia aumentou de 2 para 4\%. SAENGER et al. (1982) sugeriram a existência de correlação negativa entre o aumento da taxa de aplicação de amônia anidra e a quantidade de nitrogênio retido pelo material tratado.

Verifica-se que as equações de regressão descrevem um comportamento quadrático $(\mathrm{P}<0,01)$ na $\mathrm{RN}$, promovida por amônia anidra e uréia, em função dos níveis, porém, não houve diferença $(\mathrm{P}>0,05)$ entre os níveis para o sulfato de amônio. Estimaram-se os valores de RN em 34,00\% com 3,27\% de amônia anidra e em $33,20 \%$ com $3,42 \%$ de uréia. Entre as fontes, o sulfato de amônio resultou em maiores $(\mathrm{P}<0,5)$ retenções de nitrogênio, não havendo diferença entre amônia anidra e uréia (Tabela 7) para ambos subprodutos. A eficiência da adição de fonte de enxofre na RN também foi verificada por FAHMY e KLOPFENSTEIN (1994). A menor RN nos subprodutos tratados com amônia anidra pode ser atribuída à volatilização do gás e nos subprodutos com uréia, à baixa atividade da urease, ocorrendo reduzida liberação de amônia, ou até mesmo perda de amônia. A amonização do feno de aveia com 2 e $4 \%$ de 
SOUZA GESUALDI et al.

Tabela 7 - Efeito da interação de níveis de amônia $(X)$ e tipos de subprodutos e efeito da interação de níveis $(X)$ e fontes de amônia sobre a retenção de nitrogênio ( $Y, \%$ na $M S)$

Table 7 - Interaction effect of ammonia levels $(X)$ and byproducts types and interaction effect of levels $(X)$ and sources of ammonia on nitrogen retention ( $Y, \%$ in $D M)$

\begin{tabular}{|c|c|c|c|c|c|c|}
\hline \multirow[b]{2}{*}{$\begin{array}{l}\text { Fonte } \\
\text { Source }\end{array}$} & \multicolumn{3}{|c|}{$\begin{array}{l}\text { Nível }(\%) \\
\text { Level }\end{array}$} & \multirow[b]{2}{*}{ ER } & \multirow[b]{2}{*}{$\mathrm{R}^{2}$} & \multirow[b]{2}{*}{$\mathrm{P}$} \\
\hline & 1 & 2 & 4 & & & \\
\hline $\begin{array}{l}\text { Bagaço de cana } \\
\text { Sugar cane bagasse }\end{array}$ & $58,94^{\mathrm{a}}$ & $33,65^{\mathrm{a}}$ & $40,93^{\mathrm{a}}$ & $\hat{Y}=96,33$ & - & NS \\
\hline \multicolumn{6}{|l|}{ Sugar cane tops } & 0,0003 \\
\hline & \multicolumn{3}{|c|}{$\begin{array}{l}\text { Nível (\%) } \\
\text { Level }\end{array}$} & & & \\
\hline $\begin{array}{l}\text { Fonte } \\
\text { Source }\end{array}$ & 1 & 2 & 4 & $\mathrm{ER}$ & $\mathrm{R}^{2}$ & $\mathrm{P}$ \\
\hline $\mathrm{AA} *$ & $64,30^{\mathrm{b}}$ & $43,49^{\mathrm{b}}$ & $37,12^{b}$ & $\hat{Y}=96,86-38,43 x+5,87 x^{2}$ & 0,60 & 0,0010 \\
\hline $\mathrm{U} * *$ & $57,56^{\mathrm{b}}$ & $41,64^{\mathrm{b}}$ & $34,64^{b}$ & $\hat{Y}=81,77-28,35 x+4,14 x^{2}$ & 0,66 & 0,0003 \\
\hline $\mathrm{SA} * * *$ & $81,32^{\mathrm{a}}$ & $61,24^{\mathrm{a}}$ & $80,29^{a}$ & $\hat{Y}=71,79$ & - & NS \\
\hline
\end{tabular}

Médias seguidas das mesmas letras, na coluna, não diferem pelo teste Tukey $(P>0,05)$.

NS Não-significativo $(P>0,05)$

Means followed by same letters, in a column, did not differ by Tukey test $(P>.05)$.

NS Non significant.

* Anhydrousammonia.

** Urea.

*** Ammonia sulfate.

amônia anidra, com 15,0 e 33,3\% de umidade, promoveu retenção de compostos nitrogenados de 70,1 e $42,8 \%$ (com $33,3 \%$ de umidade) e 58,1 e $36,6 \%$ (com 15,0\% de umidade), com os respectivos níveis estudados (FERREIRA et al., 1993). Conforme REIS et al. (1995), a RN foi, em média, 78,87 e 40,97\% na palha de arroz tratada com uréia e amônia anidra, respectivamente. No feno tratado com uréia e amônia anidra, as retenções foram, respectivamente, de 99,83 e $53,9 \%$.

A análise de regressão do teor de NT após amonização, em relação aos períodos de $0,3,6,12,24$ e 48 dias para o bagaço e $0,3,6,12$ e 24 dias para a ponta, após a abertura dos silos, indicou que o modelo linear foi o que apresentou os maiores coeficientes de determinação e significâncias (Tabela 8). Os resultados revelaram que, na maioria dos tratamentos, os períodos de aeração não alteraram $(\mathrm{P}>0,05)$ o teor de NT dos subprodutos amonizados. Nota-se que, no bagaço sem tratamento, ocorreram aumentos lineares $(\mathrm{P}<0,05)$ extremamente baixos, no teor de NT ao longo dos períodos estudados. Pode ter ocorrido desenvolvimento de microrganismos, já que se tratava de material não-amonizado, apesar de não ter sido observada deterioração do bagaço. Os aumentos
$(\mathrm{P}<0,05)$ no teor de NT, verificados nos tratamentos bagaço com $2 \%$ de uréia, bagaço com $2 \%$ de sulfato de amônio e ponta com $2 \%$ de amônia anidrta, também muito pequenos, podem ser o reflexo de uma homogeneização inadequada ocorrida durante o processo de ensilagem.

Houve decréscimo $(\mathrm{P}<0,05)$ no teor de NT nos tratamentos bagaço com $4 \%$ de amônia anidra, bagaço com $4 \%$ de uréia e ponta com $1 \%$ de sulfato de amônio, no decorrer dos períodos após abertura dos silos, que também foram extremamente pequenos. PAIVA et al. (1995a) não detectaram efeito dos períodos de aeração $(0,14,28$ e 42 dias $)$ sobre o teor de NT da palhada de milho tratada com 2 e $4 \%$ de amônia anidra. Esse resultado é importante, em razão de existirem informações de que o NT, incorporado ao material no processo de amonização, poderá reduzir-se durante o período de aeração. $\mathrm{O}$ teor de NT também manteve-se estável no transcorrer do período de aeração em trabalho desenvolvido por FERREIRA (1989), com palha de arroz e feno de aveia tratada com amônia anidra. Segundo QUEIROZ et al. (1992b), os teores de PB da palha de trigo tratada com $3 \%$ de amônia anidra permaneceram altos ao final da oitava semana de aeração. 
Rev. bras. zootec.

Tabela 8 - Análise de regressão do teor de nitrogênio total do bagaço de cana (Y, em \%), em relação aos períodos (X, em dias) $0,3,6,12,24$ e 48 dias após abertura dos silos e da ponta de cana (Y, em \%), em relação aos períodos (X, em dias) $0,3,6,12$ e 24 dias

Table 8 - Fitted regressions of sugar cane bagasse total nitrogen content ( $Y$, in \%), in relation to the periods ( $X$, in days) $0,3,6,12,24$ and days after opening of the silos and sugar cane tops $(Y$, in \%), in relation to the periods ( $X$, in days) 0, 3, 6, 12 and 24 days

\begin{tabular}{|c|c|c|c|c|c|}
\hline $\begin{array}{l}\text { Tratamento } \\
\text { Treatment }\end{array}$ & $\begin{array}{l}\text { Equação regressão } \\
\text { Regression equation }\end{array}$ & $\mathrm{R}^{2}$ & $\begin{array}{c}\text { Tratamento } \\
\text { Treatment }\end{array}$ & $\begin{array}{l}\text { Equação regressão } \\
\text { Regression equation }\end{array}$ & $\mathrm{R}^{2}$ \\
\hline $\mathrm{BA} 0$ & $\hat{\mathrm{Y}}=0,31+0,008 \mathrm{x}$ & 0,30 & PA0 & $\hat{Y}=1,2$ & - \\
\hline BU0 & $\hat{Y}=0,31+0,0007 x$ & 0,30 & PU0 & $\hat{\mathrm{Y}}=1,1$ & - \\
\hline BSO & $\hat{Y}=0,30+0,008 x$ & 0,30 & PSO & $\hat{\mathrm{Y}}=1,2$ & - \\
\hline BA1 & $\hat{\mathrm{Y}}=0,54$ & - & PA1 & $\hat{\mathrm{Y}}=1,4$ & - \\
\hline BU1 & $\hat{Y}=0,57$ & - & PU1 & $\hat{Y}=1,3$ & - \\
\hline BS1 & $\hat{\mathrm{Y}}=0,83$ & - & PS1 & $\hat{Y}=1,7-0,01 x$ & 0,12 \\
\hline BA2 & $\hat{\mathrm{Y}}=0,60$ & - & PA2 & $\hat{Y}=1,5+0,02 x$ & 0,36 \\
\hline BU2 & $\hat{Y}=0,60+0,002 x$ & 0,29 & PU2 & $\hat{\mathrm{Y}}=1,3$ & - \\
\hline BS2 & $\hat{\mathrm{Y}}=0,39+0,01 \mathrm{x}$ & 0,50 & PS2 & $\hat{\mathrm{Y}}=2,3$ & - \\
\hline BA4 & $\hat{\mathrm{Y}}=0,94-0,003 \mathrm{x}$ & 0,26 & PA4 & $\hat{\mathrm{Y}}=2,1$ & - \\
\hline BU4 & $\hat{\mathrm{Y}}=0,95-0,004 \mathrm{x}$ & 0,26 & PU4 & $\hat{\mathrm{Y}}=1,6$ & - \\
\hline BS4 & $\hat{\mathrm{Y}}=1,7$ & - & PS4 & $\hat{\mathrm{Y}}=4,1$ & - \\
\hline
\end{tabular}

BA - Bagaço de cana com amônia anidra (nos níveis $0,1,2$ e 4\%, na MS).

BU - Bagaço de cana com uréia (nos níveis $0,1,2$ e $4 \%$, na MS).

BS - Bagaço de cana com sulfato de amônio (nos níveis $0,1,2$ e 4\%, na MS).

PA - Ponta de cana com amônia anidra (nos níveis $0,1,2$ e $4 \%$, na MS).

PU - Ponta de cana com uréia (nos níveis $0,1,2$ e $4 \%$, na MS).

PS - Ponta de cana com sulfato de amônio (nos níveis $0,1,2$ e 4\%, na MS).

$B A$ - Sugar cane bagasse with anhydrous ammonia (in levels 0, 1,2 and 4\%, in DM).

$B U$ - Sugar cane bagasse with urea (in levels 0, 1,2 and 4\%, in DM).

$B S$ - Sugar cane bagasse with ammonia sulfate (in levels 0, 1, 2 and 4\%, in DM).

$P A$ - Sugar cane tops with anhydrous ammonia (in levels 0, 1, 2 and 4\%, in DM).

$P U$ - Sugar cane tops with urea (in levels 0, 1, 2 and $4 \%$, in DM).

$P S$ - Sugar cane tops with ammonia sulfate (in levels 0, 1,2 and 4\%, in DM).

Foi feita a inspeção visual nos silos experimentais, em todos os períodos $(0,3,6,12,24$ e 48 dias) após abertura dos mesmos, durante a coleta de amostras. Verificou-se que o bagaço sem tratamento não apresentou sinal de deterioração durante o experimento, provavelmente, em função de seu baixo teor de umidade, o que não foi constatado na ponta. Nos silos com bagaço amonizado, houve boa preservação com todos os tratamentos usados até o último período de avaliação que foi aos 48 dias. Em relação à ponta, só foi possível coletar amostras até o 240 dia. Houve aparecimento de fungos, deteriorando totalmente todo o material. A presença de fungos ocorreu nas laterais dos silos que receberam amônia anidra, o que pode ser resultado da má distribuição do gás, causado pelo teor de umidade e pela compactação no silo. Fato semelhante foi constatado por TEIXEIRA (1990) na amonização do capim-elefante com amônia anidra. A maior deterioração dos materiais foi observada nos silos tratados com uréia e sulfato de amônio; assim, além da umidade da ponta de cana, a água usada para dissolver essas fontes de amônia aumentou ainda mais a umidade desse material, prejudicando sua conservação. A amonização com $3 \%$ de amônia anidra preservou os resíduos de arroz, soja, sorgo e milho em boas condições, não tendo sido verificada deterioração dos materiais (SILVEIRA et al., 1994).

\section{Conclusões}

Houve decréscimo no teor de FDN do bagaço e decréscimo no teor de hemicelulose da ponta, em função dos tratamentos.

A amonização com sulfato de amônio demostrou maior eficiência na redução do teor de FDA, principalmente, da ponta. Porém, no bagaço, foi detectada redução no teor de celulose, quando tratado com $1 \%$ de amônia anidra.

Foram verificados aumentos no teor de PB e diminuições na RN dos subprodutos, com elevação dos níveis de amônia. O teor de NIDA do bagaço e da ponta tratados com amônia anidra foi reduzido, porém não houve alteração do referido teor, em função das outras fontes de amônia. Não foi constatada alteração no teor de NT, na maioria dos tratamentos utilizados, em função dos períodos após abertura dos silos.

Com relação à conservação dos subprodutos, verificou-se que os benefícios resultantes dos trata- 
mentos persistiram até o 48으 dia para o bagaço e até o

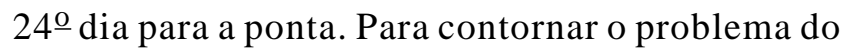
excesso de umidade, sugere-se reduzir a umidade da ponta, por meio da desidratação, e/ou reduzir a quantidade de água utilizada para dissolver a uréia e o sulfato de amônio, evitando, assim, o aparecimento de fungos.

\section{Referências Bibliográficas}

ALIBES, X., MUÑOZ, F., FACI, R. 1984. Anhydrous ammonia treated cereal straw for animal feeding. Some results from the mediterranean area. Anim. Feed Sci. Technol., 10:239-246.

ANDRIGUETTO, J. M., PERLY, L., MINARDI, I. et al. 1981. Nutrição animal: as bases e os fundamentos da nutrição animal. Os alimentos. v.1, 4.ed., São Paulo: Livraria Nobel AS. 396p.

BONJARDIM, S. R., REIS, R. A., RODRIGUES, L. R. A. et al. 1992. Avaliação da qualidade dos fenos de gramíneas tropicais armazenados com diferentes níveis de umidade e tratados com amônia. R. Bras. Zootec., 21(5):866-873.

BUETTNER, M. R., LECHTENBERG, V. L., HENDRIX, K. S. et al. 1982. Composition and digestion of ammoniated tall fescue (Festuca arundinacea Schreb.) hay. J. Anim. Sci., 54(1):173-178.

BUTOLO, J. E. Gordura protegida proveniente de subprodutos de abatedouro para ruminantes. In: SIMPÓSIO SOBRE UTILIZAÇÃO DE SUBPRODUTOS AGROINDUSTRIAIS E RESÍDUOS DE COLHEITA NA ALIMENTAÇÃO DE RUMINANTES, 1992, São Carlos. Anais... São Carlos: EMBRAPA, UEPAE, 1992. p.339-341.

FAHMY, S.T.M., KLOPFENSTEIN, T.J. 1994. Treatment with different chemical and their effects on the digestibility of maize stalks. 2. Intake and in vivo digestibility as affected by chemical treatment and monensin supplementation. Anim. Feed Sci. Technol., 45(3/4):309-316.

FERREIRA, J.Q. Efeito da amônia anidra sobre a qualidade da palha de arroz (Oryza sativa L.) e do feno de aveia (Avena strigosa Schreb.): Viçosa, MG: UFV, 1989. 110p. Tese (Mestrado em Zootecnia) - Universidade Federal de Viçosa, 1989.

FERREIRA, J. Q., GARCIA, R., QUEIROZ, A. C. et al. 1993. Efeito dos níveis de amônia anidra e dos períodos póstratamento sobre a qualidade dos fenos de aveia contendo alta ou baixa umidade. R. Bras. Zootec., 22(1):47-52.

GOERING, H.K., VAN SOEST, P.J. 1970. Forage fiber analysis: apparatus, reagents, procedure, and some applications. Washington, D.C., USDA, Agriculture Reserch Service. 20p.

GROSSI, S.F., REIS, R.A., EZEQUIEL, J.M.B. et al. 1993. Tratamento de volumosos com amônia anidra ou uréia. R. Bras. Zootec., 22(4):651-660.

NASCIMENTO, H.T.S., BONA NASCIMENTO, M.P.S.C. Tratamento de resíduos agroindustriais com uréia. In: REUNIÃO ANUAL DA SOCIEDADE BRASILEIRA DE ZOOTECNIA, 1997, Juiz de Fora. Anais... Juiz de Fora: SBZ, 1997. p.433-434.

OLIVEROS, B.A., BRITTON, R.A., KLOPFENSTEIN, T.J. 1993. Ammonia and maize stover: intake, digestibility and digestion kinetics. Anim. Feed Sci. Technol., 44:59-72.

PAIVA, J.A.J. Níveis de amônia anidra, períodos de amonização e de aeração sobre a composição químico-bromatológica e a degradabilidade "in situ” da palhada de milho (Zea mays L.). Viçosa, MG: UFV, 1992. 162p. Tese (Doutorado em
Zootecnia)-Universidade Federal de Viçosa, 1992.

PAIVA, J.A.J., GARCIA, R., QUEIROZ, A.C. et al. 1995a. Efeitos dos níveis de amônia anidra e períodos de amonização sobre os teores de compostos nitrogenados e retenção de nitrogênio na palhada de milho (Zea mays L.). R. Bras. Zootec., 24(5):672-682.

PAIVA, J.A.J., GARCIA, R., QUEIROZ, A.C. et al. 1995b. Efeitos dos níveis de amônia anidra e períodos de amonização sobre os teores dos constituintes da parede celular na palhada de milho (Zea mays L.). R. Bras. Zootec., 24(5):683-691.

PIMENTEL GOMES, F. 1973. Curso de estatística experimental. Piracicaba: USP-ESALQ. 430p.

PIRES, A.J.V. Efeito da amônia anidra sobre a conservação e composição químico-bromatológica da quirera de milho (Zea mays L.) com alta umidade: Viçosa, MG: UFV, 1995. 70p. Dissertação (Mestrado em Zootecnia) - Universidade Federal de Viçosa, 1995.

QUEIROZ, A.C., LEMENANGER, R., HENDRIX, K.S. et al. 1992a. Efeito do tratamento da palha de trigo com amônia anidra sobre a proteína bruta, digestibilidade "in vitro" da matéria seca e os componentes da fibra, após vários tempos de amonização e períodos de aeração. R. Bras. Zootec., 21(6): 1021-1028.

QUEIROZ, A.C., LEMENANGER, R., HENDRIX, K.S. et al. 1992b. Sistema de manejo alimentar para vacas de corte em gestação utilizando palha de trigo amonizada. R. Bras. Zootec., 21(6):1014-1019.

REIS, B., GARCIA, R., QUEIROZ, A.C. et al. 1991. Efeitos da amonização sobre a qualidade dos fenos de gramíneas tropicais. Pesq. Agropec. Bras., 26(8):1183-1191.

REIS, R.A., RODRIGUES, R.A., PEREIRA, J.R.A. et al. 1993. Amonização de resíduos de culturas de inverno. R. Bras. Zootec., 22(5):787-793.

REIS, R.A., RODRIGUES, L.R.A., PEDROSO, P. 1995. Avaliação de fontes de amônia para o tratamento de volumosos de baixa qualidade. R. Bras. Zootec., 24(4):486-493.

ROSA, B., REIS, R.A., PANIZZI, R.C. Ocorrência de fungos em fenos de Brachiaria decumbens Stapf cv. Basilisk submetidos à amonização. In: REUNIÃO ANUAL DA SOCIEDADE BRASILEIRA DE ZOOTECNIA, 1995, Brasília. Anais... Brasília: SBZ, 1995, p.84-85.

SAENGER, P.F., LEMENAGER, R.P., HENDRIX, K.S. 1982. Anhydrous ammonia treatment of corn stover and its effects on digestibility, intake and performance of beef cattle. J. Anim. Sci., 54(2):419-425.

SILVA, D.J. 1990. Análise de alimentos: métodos químicos e biológicos. Viçosa, MG: UFV. 165p.

SILVEIRA, V.C.P., PORTELA, J.S., OLIVEIRA, O.L.P. 1994. Utilização de resíduos agroindustriais amonizados com bovinos em regime de semi-confinamento. Ciência Rural, 24(2):375-379.

TEIXEIRA, J.R.C. Efeito da amônia anidra no valor nutritivo da palha de milho mais sabugo e do capim elefante (Pennisetum purpureum Schum.) cv. Cameroom fornecidos a novilhos nelore em confinamento: Viçosa, MG: UFV, 1990. 97p. Dissertação (Mestrado em Zootecnia) - Universidade Federal de Viçosa, 1990.

UNIVERSIDADE FEERAL DE VIÇOSA - UFV. 1995. SAEG Sistema de análise estatística e genética. Versão 5.0., Viçosa, MG.

WYLIE, A.R.G., STEEN, R.W.J. 1988. Effect of anhydrous ammonia treatment on the chemical composition and nutritive value of grass hay and on intake and performance in beef steers. Grass and Forage Sci., 43:79-86.

Recebido em: 07/04/00 Aceito em: 28/10/00 